\title{
Adhesive-bonded Repair for Cracked Metal Material of Remanufacture
}

\author{
Wenhua JIA ${ }^{1}$, Chenbo YIN ${ }^{2}$, Guo LI ${ }^{1}$, Binghui JIA ${ }^{1}$ \\ ${ }^{1}$ School of Mechanical Engineering, Nanjing Institute of Technology, Nanjing, Jiangsu, China \\ ${ }^{2}$ Institute of Automobile and Construction Machinery, Nanjing University of Technology, Nanjing, Jiangsu, China \\ crossref http://dx.doi.org/10.5755/j01.ms.23.3.17168
}

Received 30 November 2016; accepted 21 January 2017

\begin{abstract}
By investigating Q235 steel containing center cracks commonly used in construction machinery, this study analyzed the stress intensity factors at the crack tip and the crack growth rate before and after the repair of the structure. The static mechanical properties and the stress-strain at different positions of the structure were studied before and after the repair. The principle of adhesively-bonded patch repair was also verified. The obtained results showed that the static mechanical properties of the damaged metal structure were significantly improved to $80 \%$. This was done through a single-sided repair using carbon/epoxy resin. A $90 \%$ improvement was accomplished through double-sided repair.

Keywords: adhesive-bonded repair, cracked metal material, remanufacture.
\end{abstract}

\section{INTRODUCTION}

Structures with crack defects in construction machinery are traditionally repaired through screwing, riveting and welding. However, these kinds of methods can lead to new concentration and uneven distribution of stress. These methods also do not conform to the design idea of light weight. In addition, welding residual stress is supposed to occur in weld areas $[1,2]$. With the repaid development of adhesives with high performance and advanced composites [3,4], it is possible to utilize the advantages of composites in order to adhesively bond $[5,6]$ the damaged structures in the construction machinery.

By investigating Muskhelishvili theory, the researcher Nguyen Vinh Phu [7] analyzed the stress intensity factor at the crack tip of the repaired structure using a complex, variable function method. Corresponding conclusions were drawn by Carozzi [8] by simultaneously analyzing the structural stress of thin plates and considering the structures containing oval debris. Based on previous achievements, H Ayas [9] acquired a similar expression for the stress intensity factor $K$ by adding an energy release rate $G$ into the second stage of the solution process. The results acquired using this analytic method is approximate solutions. Andrieux [10] and A. Okafor [11] modelled the base board and the patch of the repaired structure using Mindlin plate elements and modelled the adhesive layer using spring elements. These models were skillfully linked by connecting the two plates and the spring using a deformation compatibility equation. Thereby, the stress intensity factor $K$ was solved based on crack closure method. Findik [12] studied the stress intensity factor $K$ by establishing a three-dimensional model. By using this model, he discovered that the simulated and experimental $K$ values of a $3.15 \mathrm{~mm}$ thick aluminum alloy plate showed a minor difference. However, this method cannot be applied in most situations and needs to divide more

\footnotetext{
* Corresponding author. Tel.: +86-13505177950.
}

E-mail address: geovrml@163.com (C. Yin) nodes, thus taking a lot of time. Furthermore, it shows various disadvantages in batch computing. The Institute for Composite Materials of Delft University of Technology in the Netherlands firstly connected structures using composites. Professor DP Roach [13] from Australia has successfully applied adhesively-bonded repair to military aircraft structures. During more than twenty years, a large number of aging aircraft have been repaired and acquired the airworthiness certificate of the Federal Aviation Administration (FAA). In addition, there are many scholars, such as Baker [14], A. Albedah [15] and K.B. Katnam [16] who have repaired the damaged structures of fighters (e.g., royal air force F-111, Hercules and Mirage) using composite patches and obtained great success. The damage to the aircraft was caused by fatigue loads or stress corrosion

The following sections of this article calculate stress intensity factors of structures before and after repair and under single-sided and double-sided repair. Then, this article analyzes the mechanical properties of the structure before and after the repair and highlights the situation of single-sided repair.

\section{THEORETICAL STUDY ON THE STRESS INTENSITY FACTOR AT THE CRACK TIP}

Suppose that there is an infinite plate with the length of the center crack being $2 a$, which is also subjected to biaxial tension, as shown in Fig. 1. This is a problem belonging to elastic mechanics. Therefore, the stress field and the displacement field, such as shown in Eq. 1 to Eq. 7 [17], nearby the crack tip can be acquired.

$$
\begin{aligned}
& \left.u=\frac{2(1+\mu) K_{I}}{4 E} \sqrt{\frac{r}{2 \pi}}\left[(2 k-1) \cos \frac{\theta}{2}-\cos \frac{3 \theta}{2}\right]\right], \\
& \left.v=\frac{2(1+\mu) K_{I}}{4 E} \sqrt{\frac{r}{2 \pi}}\left[(2 k+1) \sin \frac{\theta}{2}-\sin \frac{3 \theta}{2}\right]\right\} \\
& w=0 \\
& w=-\int \frac{\mu}{E}\left(\sigma_{x}+\sigma_{y}\right) d z
\end{aligned}
$$




$$
\left.\begin{array}{rl}
\sigma_{x} & =\frac{K_{I}}{\sqrt{2 \pi r}} \cos \frac{\theta}{2}\left(1-\sin \frac{\theta}{2} \sin \frac{3 \theta}{2}\right) \\
\sigma_{y} & =\frac{K_{I}}{\sqrt{2 \pi r}} \cos \frac{\theta}{2}\left(1+\sin \frac{\theta}{2} \sin \frac{3 \theta}{2}\right) \\
\tau_{x y} & =\frac{K_{I}}{\sqrt{2 \pi r}} \cos \frac{\theta}{2} \sin \frac{\theta}{2} \cos \frac{3 \theta}{2} \\
\tau_{x y} & =\tau_{y z}=0 \\
\sigma_{z} & =\mu\left(\sigma_{x}+\sigma_{y}\right) \\
\sigma_{z} & =0
\end{array}\right\}
$$

where $r$ and $\theta$ are the polar coordinates of the points nearby the crack tip; $u, v$ and $w$ show the components of displacement; $\sigma_{\mathrm{x}}, \sigma_{\mathrm{y}} \tau_{\mathrm{xy}}, \sigma_{\mathrm{z}}, \tau_{\mathrm{xz}}$ and $\tau_{\mathrm{yz}}$ denote the components of stress; $E$ represents the elasticity modulus. $\mu$ represents the Poisson ratio

$k=\left\{\begin{array}{l}3-4 \mu \\ \frac{3-\mu}{1+\mu}\end{array}\right.$,

where $K_{I}$ is the stress intensity factor at the crack tip. The above formulas can be simplified as follows:

$$
\begin{aligned}
& \sigma_{i j}^{(I)}=\frac{K_{I}}{\sqrt{2 \pi r}} f_{i j}^{(I)}(\theta) ; \\
& u_{i}^{(I)}=K_{I} \sqrt{\frac{r}{\pi}} g_{i}^{(I)}(\theta),
\end{aligned}
$$

where $\sigma_{\mathrm{ij}}(i, j=1,2,3)$ and $u_{\mathrm{i}}(i=1,2,3)$ show the components of stress and displacement, separately; the superscript $(I)$ represents the I type; $f_{\mathrm{ij}}(\theta)$ and $g_{i}(\theta)$ denote the functions of the polar angle $\theta$, respectively.

The stress intensity factor can generally be expressed as follows:

$$
K_{I}=Y \sigma \sqrt{\pi a},
$$

where $\sigma$ is the nominal stress; $a$ shows the size (length or depth) of cracks; $Y$ indicates the shape factor, which is related to the size and position of cracks. The stress intensity factor is generally measured in $\mathrm{kg} \cdot \mathrm{mm}^{-3 / 2}$.

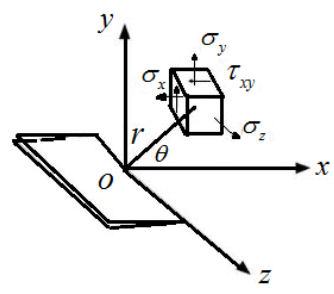

Fig. 1. Stress field and displacement field near the crack tip

The cracked metal plate was repaired using composite patches based on an adhesively-bonded repair technique. The repaired structure was mainly composed of three parts, shown in Fig. 2. According to the sequence of the parts used in the repair technique, the first part referred to the cracked base metal. The adhesive layer and the composite patch, together, are the second and third parts. The repair model built in this study was repaired with single-sided and double-sided patches, separately. The corresponding stress intensity factors of the cracks were calculated using MATLAB software. The base metal applied was Q235 steel with the following size: $200 \mathrm{~mm}$ x $80 \mathrm{~mm} \times 5 \mathrm{~mm}$ (length $\mathrm{L} 1 \times$ width B $1 \times$ thickness T1). At the center of the plate, a crack was observed $24 \mathrm{~mm}$ in length. That is, $2 a=24 \mathrm{~mm}$, where $a$ means the half length of the crack.

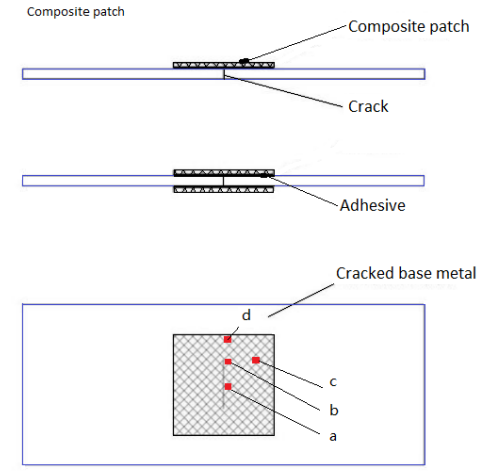

Fig. 2. Schematic diagram of gluing structure
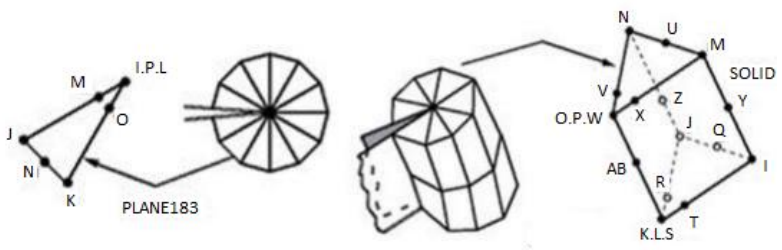

Fig. 3. Crack tip grid

Fig. 3 illustrates the grid at the crack tip where there is a great stress gradient. In Fig. 3, the letter has no actual meaning, but only the grid node. To capture such stress variation, the grids in the stress-induced deformed zone need to be refined.

\section{STRESS INTENSITY FACTORS OF THE ADHESIVELY REPAIRED STRUCTURE}

According to the displacement Eq. 2 nearby the tip of the I-typed crack, the following is true:

$u_{i}(r, 0)=\frac{2(1+\mu) K_{I}}{E} \sqrt{\frac{r}{2 \pi}} f_{i}(\theta), i=1,2$

Where, $u_{1}=u, u_{2}=\mu$

$f_{1}(\theta)=\frac{1}{4}\left[(2 k-1) \cos \frac{\theta}{2}-\cos \frac{3 \theta}{2}\right]$
$f_{2}(\theta)=\frac{1}{4}\left[(2 k+1) \sin \frac{\theta}{2}-\sin \frac{3 \theta}{2}\right]$.

$k=\frac{3-\mu}{1+\mu}$

$k=3-4 \mu$

Thus, it can be seen that $K_{I}$ can be acquired by substituting the displacement $u_{\mathrm{i}}$, which is calculated using the finite element method (FEM) in Eq. 8.

In general, the crack opening displacement, $v(r, \pi)$, when $\theta=\pi$, is applied to solve $K_{I}$. This is because the opening displacement $v$ at this time is prominent. Therefore, the exact solution can be easily acquired under the following condition:

$$
K_{I}(r, \pi)=\frac{E}{(1+\mu)(k+1)} \sqrt{\frac{2 \pi}{r} \mu}(r, \pi) .
$$


The solution acquired using the above formula nearby the crack tip $(r \rightarrow 0)$ is exact. This is because it merely saves the singular items of $r$. However, the stress intensity factor $K_{I}$ at the position far away from the crack tip is no longer a constant. Therefore, the displacement can only be obtained through different $r$ values along the crack surface. Curves were drawn after solving the corresponding $K_{I}$ values using the above formula, $K_{I}-r$. When $r$ was small, the fitted curve of all points approximated to a straight line, while the vertical intercept of the line, in this case, was the required $K_{I}$.

To verify the accuracy of the built model, the simulated and theoretical values of the model were compared to calculate the error range. Table 1 illustrates the simulated results acquired using the established model.

Table 1. Result of displacement method

\begin{tabular}{|c|c|c|c|c|}
\hline $\begin{array}{c}\text { Serial } \\
\text { number }\end{array}$ & $\begin{array}{c}\text { Node } \\
\text { number }\end{array}$ & $\begin{array}{c}\text { Abscissa, } \\
\mathrm{mm}\end{array}$ & $\begin{array}{c}\text { Displacement, } \\
10^{-2} \mathrm{~mm}\end{array}$ & $\begin{array}{c}\text { Stress intensity } \\
\text { factor, } \\
\mathrm{K} / \mathrm{MPa} \sqrt{\mathrm{mm}}\end{array}$ \\
\hline 1 & 662 & 1.00 & 0.51 & 674 \\
\hline 2 & 660 & 1.50 & 0.62 & 669.4 \\
\hline 3 & 658 & 2.06 & 0.72 & 663.3 \\
\hline 4 & 640 & 2.68 & 0.81 & 654.2 \\
\hline 5 & 638 & 3.37 & 0.89 & 641.0 \\
\hline 6 & 636 & 4.14 & 0.97 & 630.4 \\
\hline 7 & 573 & 5.00 & 1.00 & 591.3 \\
\hline 8 & 8150 & 6.70 & 1.14 & 591.0 \\
\hline 9 & 8148 & 8.50 & 1.20 & 544.2 \\
\hline
\end{tabular}

A coordinate system was made using the abscissa of all points, as well as stress intensity factors listed in the above table as the abscissa and the ordinate, separately, to perform linear fitting and solve the vertical intercept (the required stress intensity factor). After linear fitting, the ordinate was obtained as $693 \mathrm{MPa} \sqrt{\mathrm{mm}}$, which showed an absolute error of $47.7 \mathrm{MPa}$ and a relative error of merely $7 \%$ in comparison with the theoretical value 645.3 MPa of Arin [18]. This accuracy satisfied the requirement, indicating that the finite element model built in this research was correct.

Adhesively-bonded repair is supposed to adopt doublesided repair wherever possible in order to meet the requirement of light weight. This study tested the mechanical properties of cracked metal plates after adhesively-bonded repair by using the MTS-880 hydraulic universal testing machine (MTS System Corporation). This experiment was controlled through the computer terminal of the host computer. The obtained results are demonstrated in Table 2.

Table 2. Result of displacement method

\begin{tabular}{|c|c|c|c|c|}
\hline $\begin{array}{c}\text { Fracture load, } \\
\text { KN }\end{array}$ & 150.4 & 105.4 & 104.6 & 103.2 \\
\cline { 2 - 5 } & 376 & 263.75 & 261.5 & 258 \\
\hline $\begin{array}{c}\text { Fracture } \\
\text { strength, MPa }\end{array}$ & 93.2 & 65.8 & 79.2 & 90.8 \\
\hline $\begin{array}{c}\text { Degumming } \\
\text { load, KN }\end{array}$ & 233 & 164.5 & 198 & 227 \\
\hline $\begin{array}{c}\text { Yield strength, } \\
\mathrm{MPa}\end{array}$ & $/$ & 70 & 69 & 68 \\
\hline$\eta / \%$ & & & & \\
\hline
\end{tabular}

I1: Intact metal plate, I2: Unrepaired cracked metal plate, I3: Cracked metal plates repaired with single-sided patches, I4: Cracked metal plates repaired with doublesided patches.

Table 2 exhibits the tensile fracture, yield and debonding loads, as well as the residual bearing capacity obtained from the intact metal plate, unrepaired plate, single-sided repaired plate and double-sided repaired plate in the experiment. $\eta$ is the residual rate of the bearing capacity. According to the table, owing to the presence of the center crack, the bearing capacity of the metal plate was significantly reduced to merely $105.4 \mathrm{KN}$. Furthermore, the $\eta$ value was equal to $70 \%$ of the original one. For the metal plate with one side repaired, the yield load was recovered to about $80 \%$ and could be utilized temporarily in some cases, which made a low requirement. In contrast, the yield load of the plate with both sides repaired was restored to over $90 \%$, showing that the structure performance has basically been restored.

All cracked plates showed a crack in the length of $2 a=24 \mathrm{~mm}$. The model was subjected to the tensile load of $100 \mathrm{MPa}$.

Fig. 5 depicts the stress-strain relation of the repaired metal plate under the effect of unidirectional tensile loads.

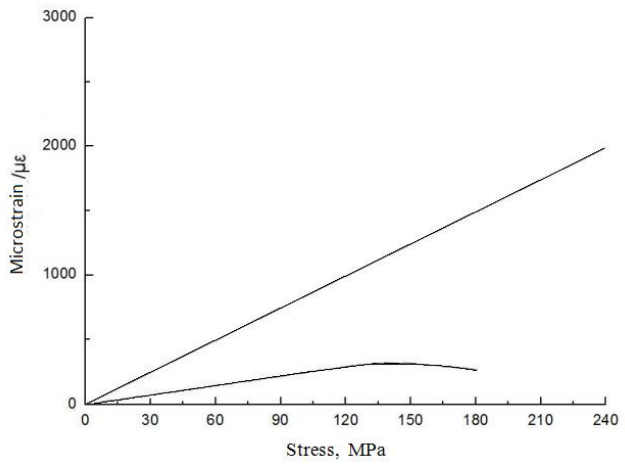

a

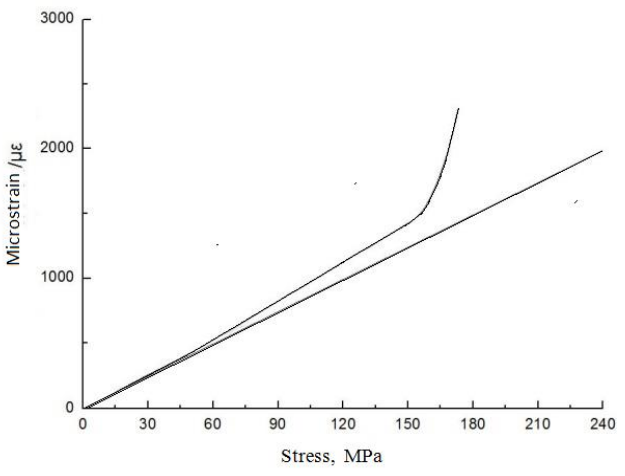

b

Fig. 5. Relatively far away from the crack site: a-middle of the crack in the crack zones; b-on the crack's tip in the crack zones

As can be seen, after the center of the metal plate was cracked, the stress distribution at each point in the plane was quite different. Owing to the existence of the crack, the stress that was distributed was changed in the plane.

In the region away from the crack zones, the stressstrain at each test point was under control and linearly varied with the increasing loads. This approximately accorded with the finite element analysis and conformed to 
the local disturbance. In the crack zones (Fig. 5 and Fig. 6), the strain distribution at each test point significantly changed. When the metal plate was subjected to small loads, the micro strain at each test point linearly varied with the growing loads. Meanwhile, it nonlinearly rose when the load exceeded a certain value.

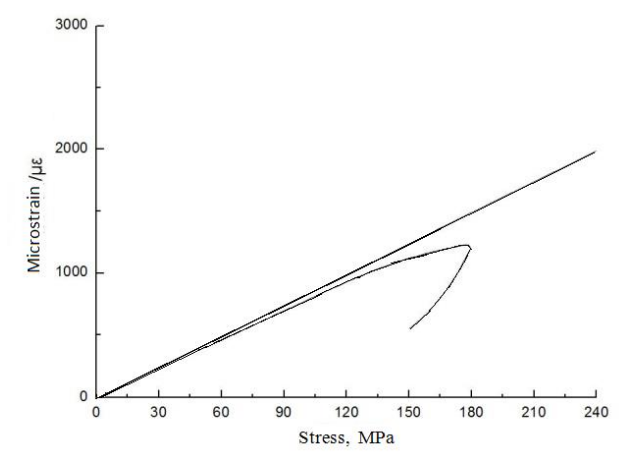

a

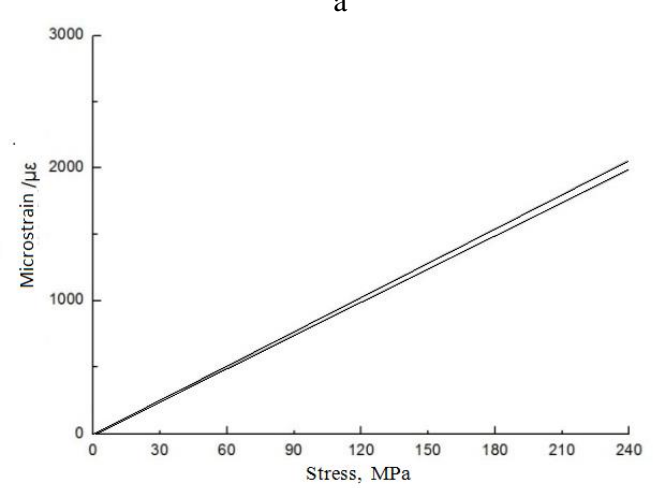

b

Fig. 6. Relatively far away from the crack site: $a-$ on the right side of the middle crack in the crack zones zones; $\mathrm{b}$ - relatively far away from the crack site

We pasted a strain gauge (a) at the middle of the crack in the crack zones (a, b, c, d), as shown in Fig. 2. This location needed particular attention since the crack's existence made the micro strain extremely small, certainly smaller than the strain in the far-field region. Hence, the indication was that the load placed on this section was comparably small. We then pasted the strain gage (b), on the crack's tip, whose existence determined a relatively significant stress concentration in the area. Therefore, the region's micro strain was greater than the strain in the farfield region, revealing that in similar structures this section typically bears a heavier load. However, based on our experiments, we found that when we increased the stress to $160 \mathrm{MPa}$, the micro strain in the crack's tip (b) experienced an obvious reduction, indicating the occurrence of crack propagation. The strain gage (d)'s location was relatively far away from the crack site, and the micro strain presented a linear variation below $160 \mathrm{MPa}$. After the stress value exceeded $160 \mathrm{MPa}$, nearby micro strains also exhibited an obvious increase. Hence, we may conclude that crack propagation led to the crack's tip extending outward to the strain gage (b)'s surrounding area. This, in turn, resulted in further stress concentration in this area.

The prefabricated metal plate containing center cracks was repaired with single-sided patches. Resistance strain gauges were stuck at the same position on the corresponding side of the composite and the metal plate. In this way, micro strain can be tested by loading external tensile loads. Thus, this verifies the repair principle and the exploring the conditions of the load that is acted upon by the patch. It was found that the patch of the single side that was adhesively-bonded to the repaired patch had a load of about $20-30 \%$. This significantly reduces the load of the structure itself.

The stress-strain curves at each test point are illustrated in Fig. 7. As can be seen, obvious strain happened to the composite patch. These results validate the working principle of adhesively-bonded repair.

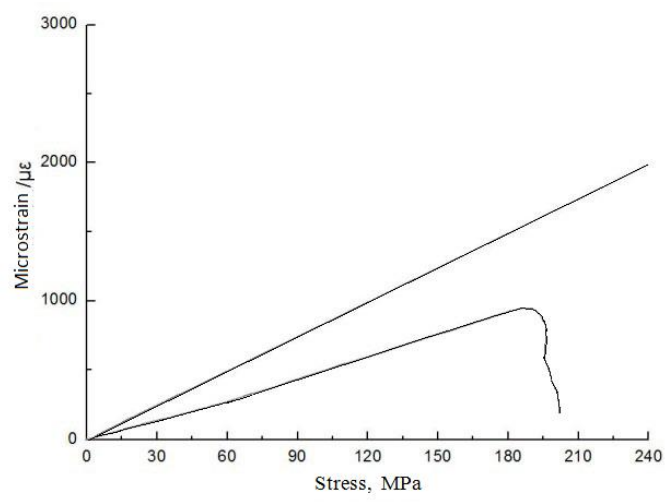

a

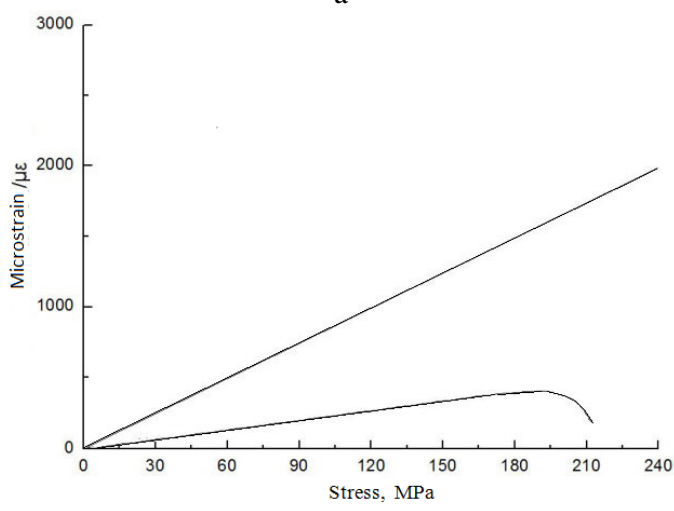

b

Fig. 7. Patch surface stress - micro-strain curve: a-patches on the crack's tip in the crack zones; $b$ - patches on the middle of the crack in the crack zones

\section{CONCLUSIONS}

This research calculated the stress intensity factors of structures before and after repair and under single-sided and double-sided repair. Meanwhile, the influence of various factors on the stress intensity factor of the repaired structure were analyzed through a large amount of simulations. These factors included the length of the crack, patch material, the geometrical parameters (length, width and thickness) of patches and the shear modulus and thickness of adhesives.

This research analyzed the mechanical properties of the structure before and after the repair and highlighted the situation of single-sided repair. This research verified the working principle of a repair technique by studying the stress-strain of the structure at different positions before and after the adhesively-bonded patch repair. In addition, it 
was discovered that the patch in the model bore about $30 \%$ of the total load that was applied to the structure.

\section{Acknowledgments}

This work was supported in part by The National Natural Science Fund of China, Jiangsu Natural Science Foundation, University of Jiangsu Natural Science Foundation, and SANY Co., Ltd. in Jiangsu. Lecturer, Support Fund Nos. 51505211, 51505212, 51405222, 11302097.

\section{REFERENCES}

1. Xueqin, L., Honghai, J., Guofu, Y. Detection of Surface Crack Defects on Ferrite Magnetic tile NDT and E International 62 2014: pp. 6-13. https://doi.org/10.1016/j.ndteint.2013.10.006

2. Wang, W., Wei, HX., Zhen, Y. Nondestructive Evaluation of Welding Crack Defects in Structural Component of Track Crane using Acoustic Emission Technique Intelligent automation and soft computing $18(18)$ 2012: pp. 513-523.

3. Shalbafan, A., Welling, J., Hasch, J. Geopolymers as Potential New Binder Class for the Wood based Composite Industry Holzforschung 70 (8) 2016: pp. 755-762.

4. Kierzek, K. Influence of Binder Adhesion Ability on the Performance of Silicon/Carbon Composite as Li-Ion Battery Anode Journal of Materials Engineering and Performance 25 (6) 2016: pp. 2326-2335. https://doi.org/10.1007/s11665-016-2083-7

5. Myers, K., Juhasz, M., Cortes, P., Conner, B. Mechanical Modelling based on Numerical Homogenization of an $\mathrm{Al}_{2} \mathrm{O}_{3} /$ Alcomposite Manufactured via Binder Jet Printing Computational Materials Science A 108 2015: pp. 128-135.

6. Zhou, X., Yang, J.Z., Su, D.P., Qu, G.H. The High Temperatu- re Resistant Mechanism of $\alpha$-starch Composite Binder for Foundry Journal of Materials Processing Technology 209 (14) 2009: pp. 5394-5398.

7. Nguyen, V.P., Anitescu, C., Bordas Stéphane, P.A. Isogeometric Analysis: An Overview and Computer Implementation Aspects Mathematics and Computers in Simulation 117 2015: pp. 89-116.

8. Carozzi, F.G., Colombi, P., Fava, G. A Cohesive Interface Crack Model for the Matrix-textile Debonding in FRCM
Composites Composite Struct-tues 143 2016: pp. 230241.

9. Ayas, H., Benzahar, H., Chabaat, M. Energy Release Rate during the Cracking of Composite Materials In The International Conference on Technologies and Materials for Renewable Energy Environment and Sustainability-TMRESS 15, Energy Procedia 74 2015: pp. 1040-1047. https://doi.org/10.1016/j.egypro.2015.07.742

10. Andrieux, S., Baranger, T.N. Three-dimensional Recovery of Stress Intensity Factors and Energy Release Rates from Surface Full-field Displacements International Journal of Solids And Structures 50 (10) 2013: pp. 1523-1537.

11. Okafor, A.C., Singh, N., Enemuoh, U.E. Design, Analysis and Performance of Adhesively Bonded Composite Patch Repair of Cracked Aluminum Aircraft Panels Composite Structures 71 (2) 2005: pp. 258-270.

12. Findik, F., Mrad, N., Johnston, A. Strain Monitoring in Composite Patched Structures Composite Structures 49 (3) 2000: pp. $331-338$.

13. Roach, D.P., Scala, C.M. Non-Destructive Evaluation and Quality Control for Bonded Composite Repair of Metallic Aircraft Structures Advances in the Bonded Composite Repair of Metallic Aircraft Structure 2002: pp. 659-726. https://doi.org/10.1016/B978-008042699-0/50025-5

14. Baker, A.A. Bonded Composite Repair of Fatigue Cracked Pri-mary Aircraft Structure Composite Structures 47 1999: pp. $431-443$.

15. Albedah, A., Benyahia, F., Dinar, H. Analytical Formulation of the Stress Intensity Factor for Crack Emanating from Central Holes and Repaired with Bonded Composite Patch in Aircraft Structures Composites Part B Engineering 45 (1) 2013: pp. 852-857.

16. Katnam, K.B., Da Silva, L.F.M., Young, T.M. Bonded Repair of Composite Aircraft Structures: A Review of Scientific Challenges and Opportunities Progress in Aerosp-ace Sciences 61 2013: pp. 26-42.

17. Erdogan, F., Arin, K.A. Sandwich Plate with a Part-through and a Debonding Crack Engineering Fracture Mechanics 2 1972: pp. 449-458.

18. Ahonsi, B., Aleyaasin, M., Harrigan, J.J. On the propagation Coefficient Of Longitudinal Stress Waves In Viscoelastic Bars International journal of impact engineering 45 2012: pp. 39-52.

https://doi.org/10.1016/j.ijimpeng.2012.01.004 